\title{
Proposal for an SMS-driven CMMS solution
}

\author{
Dieudonné Abessolo Assoumou ${ }^{1}$, Aimé Joseph Oyobé Okassa ${ }^{2}$, Pierre Élé ${ }^{3}$ \\ ${ }^{1,2}$ Ecole Polytechnique, Université des Sciences et Techniques de Masuku, Franceville, Gabon \\ 1'assoumouad@gmail.com \\ 2oyobeokassa@yahoo.fr \\ ${ }^{3}$ Ecole Polytechnique, Université de Yaoundé I, Yaoundé, Cameroun \\ ${ }^{3}$ IUT, Université de Douala, Douala, Cameroun \\ ${ }^{3}$ pierre_ele@yahoo.fr
}

\begin{abstract}
The current possibilities for accessing and using CMMS software remotely are essentially through the use of the Internet. This is a major challenge in areas not served by the global network; this is the case in developing countries where only large towns are covered.

The purpose of this article is to propose an alternative solution, which uses SMS. After a review of the literature, on the possibilities of using SMSs and existing remote access solutions for CMMS tools, a proposal for using short messages as a solution for the remote use of CMMS software is presented and implemented, as part of the maintenance of medical equipment in two medical structures in Cameroon and Gabon.
\end{abstract}

The results obtained show that the GSM-SMS technology can be used in a relevant and effective way in a context of managing the maintenance of medical equipment to provide mobility and remote control of CMMS software.

\section{Maintenance, CMMS, SMS, Internet, Remote Control}

\section{INTRODUCTION}

In a context of development research, African countries must put a lot of effort into achieving their emergence goals. Among the challenges imposed on them, they have the obligation to succeed with very limited financial means. In such a context, it is important that the populations, first vital forces of these states, be in excellent health. This good state of health requires good maintenance of medical devices.

Today, no medical facility can be effective without a well-equipped and operational technical platform. Indeed, the first global forum on medical devices in 2012 was an opportunity to remind and specially to raise awareness of the key role played by medical devices in the prevention, diagnosis and treatment of diseases and in the rehabilitation [1]. This directly involves the maintenance of the medical equipment that compose it and more precisely the effective management of this maintenance. Nowadays, the issue of computer-assisted maintenance management tools no longer arises in terms of necessity, but rather in terms of efficiency that depends on the end-user [2]. Most of the time, the CMMS software is a web application, hosted on the company's server or on a remote server, whose access is only possible via the Internet. In both cases, users need to install in front of a workstation connected to the corporate network or the internet. This drastically reduces the mobility of maintenance agents. In this article we propose a solution to give more freedom to the personnel in charge of managing maintenance in a medical structure.

The plan of this article is articulated as follows. After this introduction, follows successively the review of the literature, the methodology, the material used in the test bench, the results and discussions, then the conclusion.

\section{LITERATURE REVIEW}

In 2012, the World Health Organization (WHO) issued a series of technical publications entitled "WHO Technical Series on Medical Devices", as guidance and advice, for park management, maintenance and maintenance management of medical equipment $[1,3,4,5]$. This shows the importance of rigorous monitoring of medical devices. With regard to Yaoundé Central Hospital in Cameroon, the implementation of a CMMS solution, in partnership with the National Polytechnic School of Yaoundé has been taking shape for some time [6]. This project suffers from a lack of mobility as it can only work in a local network, and immaturity because it has not been conducted to a satisfactory level for use.

The main features offered by such a tool are: equipment management, maintenance management (corrective and preventive), inventory management, security management, purchasing management, key performance indicators, ... For the moment, working with such a tool, even in the case of a deployment in a computer network, is only possible if the users are in the presence of a workstation like computer, connected to the corporate network. 
This poses a problem accessing this work tool when access to the corporate network is not available. However, because of the very sensitive roles played by the different medical devices, it would be wise to reduce their downtime to a minimum.

In Cameroon, more than $80 \%$ of the country's localities are covered by at least one GSM network since 2015 [7]. This is an opportunity for those who are in the areas covered to use the services of short messages (SMS), which can be used for purposes other than the usual communication between individuals. In a study conducted in 2014, Amin and Khan show that, not only is this possible, but also that SMS is well suited to other types of uses [8].

In the field of health, several cases of use of SMS have been envisaged. Ben Townsend and his team used mobile technologies and SMS messaging for the transmission of non-critical medical telemetry from medical sensor data. Their goals were to increase freedom and reduce costs for patients under medical supervision [9]. In the same vein, Manita Rajput and her team also used SMS for monitoring patients with cardiovascular disease. Their approach was to implement a system that alerts the treating physician by SMS, when the monitored parameters reach critical values [10]. In their article [11], Fogg and Allen go further and present ten (10) possible uses of this technology for overall health improvement. These use cases are summarized in Table I.

TABLE I. Some uses of SMS for overall health improvement [11]

\begin{tabular}{|l|l|}
\hline Categories & Details \\
\hline - Sending Info to Users & - Educating People, \\
& - Notifying People, \\
& - Reminding People, \\
\hline - Gathering Info from Users & - Collecting Data from People, \\
& - Journaling by Individuals, \\
\hline - User Questions \& Expert Response & - Getting Answers from a Database, \\
& - Getting Answers from a Person, \\
\hline - People-to-People Connection & - Connecting Individuals, \\
\hline - Transactions & - Connecting Groups, \\
\hline
\end{tabular}

In the agricultural field, Tseng and his team used GSM-SMS technology for monitoring and collecting data (temperature, humidity, wind speed and number of insects / pests caught, etc.) on farms [12].

These examples, which illustrate some possibilities for using short messages, have in common the fact of not referring to maintenance management or maintenance management software.

The modern challenges of profitability and efficiency require organizations to go as close as possible to the source of information in order to facilitate its collection and specially to make it available as soon as possible for rapid decision-making, for example. This results in the availability of tools and equipment needed in the field and often far from the office. These needs for collaborative work and information sharing are not new. In 2003, as part of the European project MOTION, Dustdar and Gall propose a collaborative and mobile work architecture [13]. In 2006, Arnaiz et al. present the potential of ubiquitous computing in the practice of industrial maintenance, as well as a vision of solutions for mobile maintenance, both implemented within the framework of the European project DYNAMITE 017498 [14]. They continue their scientific research in the same direction in 2009, with a focus on conditional maintenance [15]. Central Arkansas Water has been able to improve the efficiency of its water distribution and treatment infrastructure maintenance activities, through the use of a CMMS tool with a geographic information system associated with it, which were deployed on mobile devices in 2009 [16]. In a literature review conducted in 2009, Emmanouilidis et al. find a penetration, albeit at different but sustained scales, of mobile technologies in asset management and industrial maintenance [17]. Later on, in 2014, Bankosz and Kerins developed a prototype to demonstrate the benefits of deploying mobile technology to improve maintenance in a small food manufacturing plant [18]. To meet the specific needs of some companies in charge of maintenance on various sites, where transmission of data in real time is vital, Zhao and Feng have designed and implemented a CMMS system accessible by mobile devices running on Android [19]. In the maritime domain, new information technologies have been used to improve the management of maintenance and monitoring of the parameters of a vessel, to the point that the conditions of the equipment of a ship at sea are known, in real time by staff left on the ground [20]. Similarly, Munyensanga et al. used an application deployed on mobile devices running Android, for improved efficiency of preventive maintenance of a circulation pump intake system [21].

These works have in common the use of the internet as a means of communication between equipments. 
The use of current CMMS software forces their users either to have a good internet connection (this is not often possible in developing countries), or to work directly on a workstation connected to the local network; this limits their access to this work tool, during hours of service and service locations only.

Despite the large number of these works on the themes of the use of SMSs in various fields, or the search for mobility in the management of maintenance, the use of SMS has not yet been tested for the management of maintenance of medical equipment.

\section{Methodology}

To achieve our goals, we adopted an incremental approach, consisting of a progressive implementation of the functions of CMMS commands by SMSs.

In this work we present the effectiveness of a complete cycle of preventive maintenance. The method is described according to the diagram of figure 1.

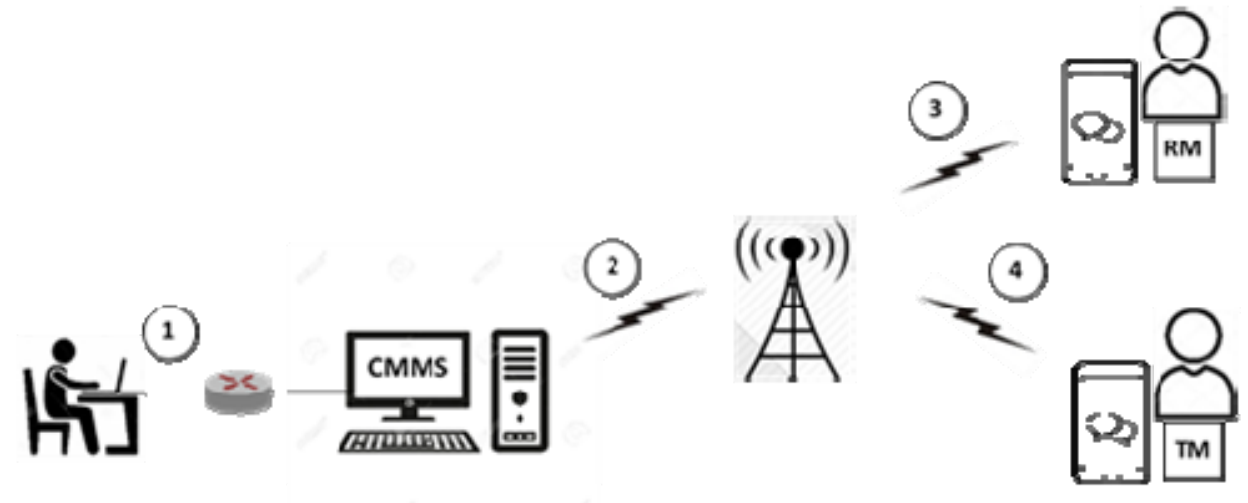

Fig. 1. Schematic diagram of the experimental system

Figure 1 illustrates the data exchange during a preventive maintenance cycle that we propose to solve the problem, namely: access and interact with a CMMS software by SMSs. We describe a preventive maintenance cycle such as the process from scheduling a preventive maintenance plan to the report after the completion of the corresponding work.

The preventive maintenance cycle is as follows:

a. Information about preventive maintenance plans for medical equipment is stored in the database, from a workstation. This is path (1).

b. As soon as an equipment is put into operation, the current date of the system is continuously compared to the dates of the maintenance schedule deadlines. At the end of a deadline, the system sends by SMS a notification to the maintenance manager RM, along paths (2) and (3).

c. The RM maintenance manager assigns a maintenance technician TM to this task via SMS, following paths (3) and (2), then (2) and (4)

d. The maintenance technician TM asks the system for the details of the work to be done, along paths (4). and (2).

e. The system responds by sending the list of required materials, as well as the procedures for performing maintenance tasks, along paths (2) and (4).

f. After completion of the work, the technician makes records that he sends by SMS to the CMMS, following the paths $(4)$ and (2).

g. The maintenance manager can then verify that the maintenance has been performed correctly, by querying the system and knowing the execution status of the task, along the paths (2) and (3), then (3) and (2).

Currently, the operation of a web application installed on a remote server is characterized by a series of interactions (requests-responses) with users, through web browser installed on workstations and web server application deployed on server side. In our case, in addition to this usual mode of operation, the system needs to perform a functional autonomy. Indeed, several actions must be executed spontaneously, and not in response to a request initiated by a human operator. In this sense, we can mention the update of preventive maintenance programs, the sending of notifications by SMS when the deadlines are reached, the reading and the processing of incoming SMSs. This is how our system will be able to perform all the tasks entrusted to it, at any time of the day. The different components that come into play during this process are shown in Figure 2. 


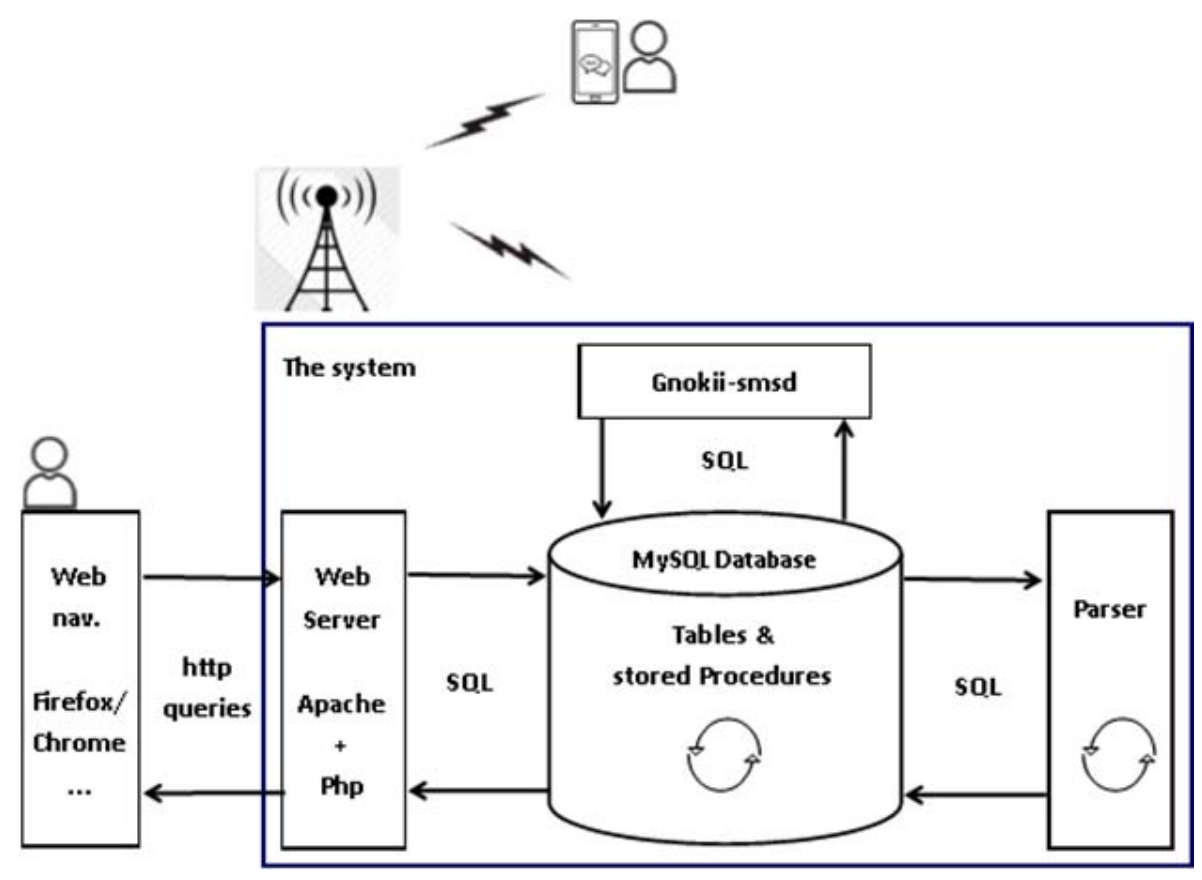

Fig. 2. The components of automatic operation

This automatic operation is carried out as follows:

- The sending and receiving of SMSs is supported by the tool gnokii-smsd, which allows to read and send SMSs, independently and periodically. When connected to a database, incoming messages are put into one table, while outgoing messages must be put into another table. In either case, each message has a token indicating whether the message has been sent (for outgoing messages), or whether it has been processed by the parser, for incoming messages.

- Updating maintenance plans is processed by procedures stored in the MySQL database. At regular intervals, the periodic installments are compared to the current date. In case of a match, notifications are "dropped" in the outgoing SMS table, where they are supported by gnokii-smsd.

- The parser reads the incoming SMSs, interprets their contents and executes the actions requested by the users. The actions processed are the issuance of requests for the details of the maintenance procedures, the receipt of the maintenance reports, the updating and the issuance of the execution reports of the maintenance works.

\section{MATERIAL}

The system we propose includes a hardware part and a software part.

The material components include:

- A laptop (Lenovo Thinkpad T500) running Linux Ubuntu 16.04.

- A laptop (Lenovo Thinkpad W541) running Windows 10 Pro.

- A modem (Huawei E220) equipped with a SIM card used to access the GSM network.

- A Samsung Galaxy Tab 4 tablet, running Android 5.0.2.

The software components are:

- HospiMaint, a CMMS software currently being developed with the Laravel 5.5 framework. HospiMaint is inspired by maintenancedb [22], a former CMMS project abandoned by his author, main concepts of which have been taken up and improved.

- gnokii-smsd (version 0.6.31): tool that manages the automatic sending and receiving of SMS using a MySQL database.

- A MySQL database server (version 5.7.19) running on the Ubuntu 16.04 desktop operating system.

- A parser that reads the SMS and executes their contents in the CMMS software.

- A client application, running on mobile devices equipped with the Android system, for sending and receiving short messages. 
As working tools, we have:

- Android Studio 3.3, for the development of the module running Android.

- Eclipse Oxygen Release (4.7.0), for the development of modules running on PC.

- Laravel 5.5, a PHP framework for developing dynamic web-type applications.

\section{RESULTS AND DISCUSSION}

In this paper, medical equipment data from the medical analysis laboratory of a Regional Hospital of Gabon were used to validate our methodology.

As shown in the following screenshots, we have implemented a complete preventive maintenance cycle and the maintenance manager can check the status of each task. Some apparatuses of a technical platform of the Regional Hospital are listed in figure 3.

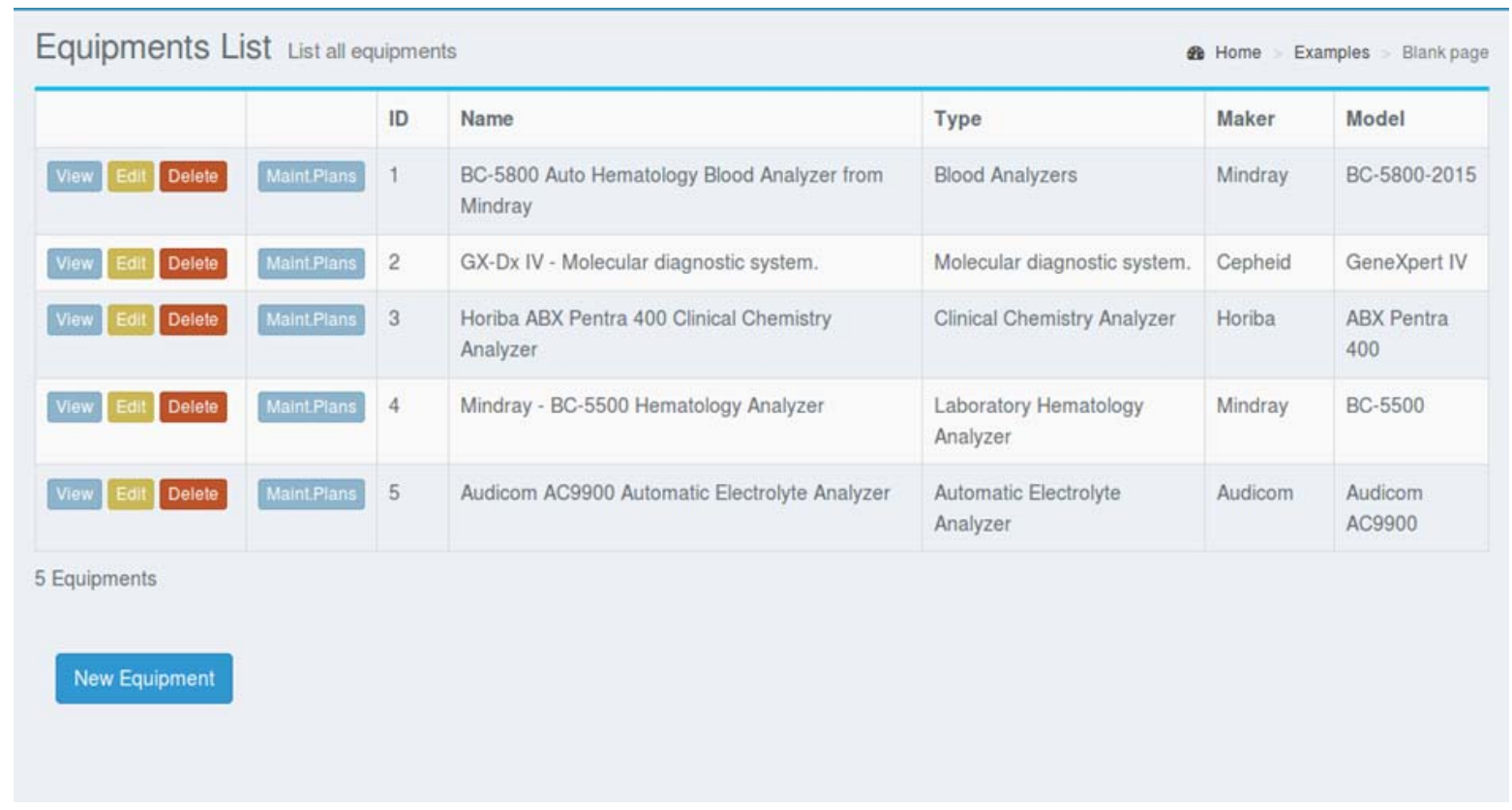

Fig. 3. List of a few medical equipments of a Regional Hospital

Figure 3 shows the equipment selected for this work. They were filled in the CMMS application by a user using a computer connected to the corporate network. One selected device is shown in figure 4.

\begin{tabular}{|c|c|c|c|c|c|}
\hline \multicolumn{4}{|c|}{ View Equipment view equipment data } & A Home Examples & Blank page \\
\hline & ID & \multicolumn{2}{|l|}{2} & & \\
\hline & Name & \multicolumn{2}{|l|}{ GX-Dx IV - Molecular diagnostic system. } & & \\
\hline & Type & \multicolumn{2}{|l|}{ Molecular diagnostic system. } & & \\
\hline & Maker & \multicolumn{2}{|l|}{ Cepheid } & & \\
\hline & Mark & \multicolumn{2}{|l|}{ Cepheid } & & \\
\hline & Model & \multicolumn{2}{|l|}{ GeneXpert IV } & & \\
\hline \multicolumn{6}{|c|}{ View all equipments } \\
\hline \multicolumn{3}{|c|}{ Maintenance Plans } & & & $-x$ \\
\hline ID & Period & Title & Part & Group & \\
\hline 1 & one Month & Cleaning the Instrument Surfaces & Body & Mechanic & \\
\hline 2 & one Month & Cleaning the Cartridge Bays & Cartridge Bays & Mechanic & \\
\hline 3 & one Month & Cleaning the Plunger Rods & Plunger Rods & Mechanic & \\
\hline
\end{tabular}

Fig. 4. List of Equipment Maintenance Plans GeneXpert Dx System GX-IV R2Dx 
Figure 4 shows the list of preventive maintenance plans for GeneXpert DX, a medical biology analyzer. As soon as an equipment is put into operation, the system monitors the deadlines for each maintenance plan, for each medical device. At the end of a deadline, the system updates the monitoring of the maintenance, adding for each device, the future actions to be executed.

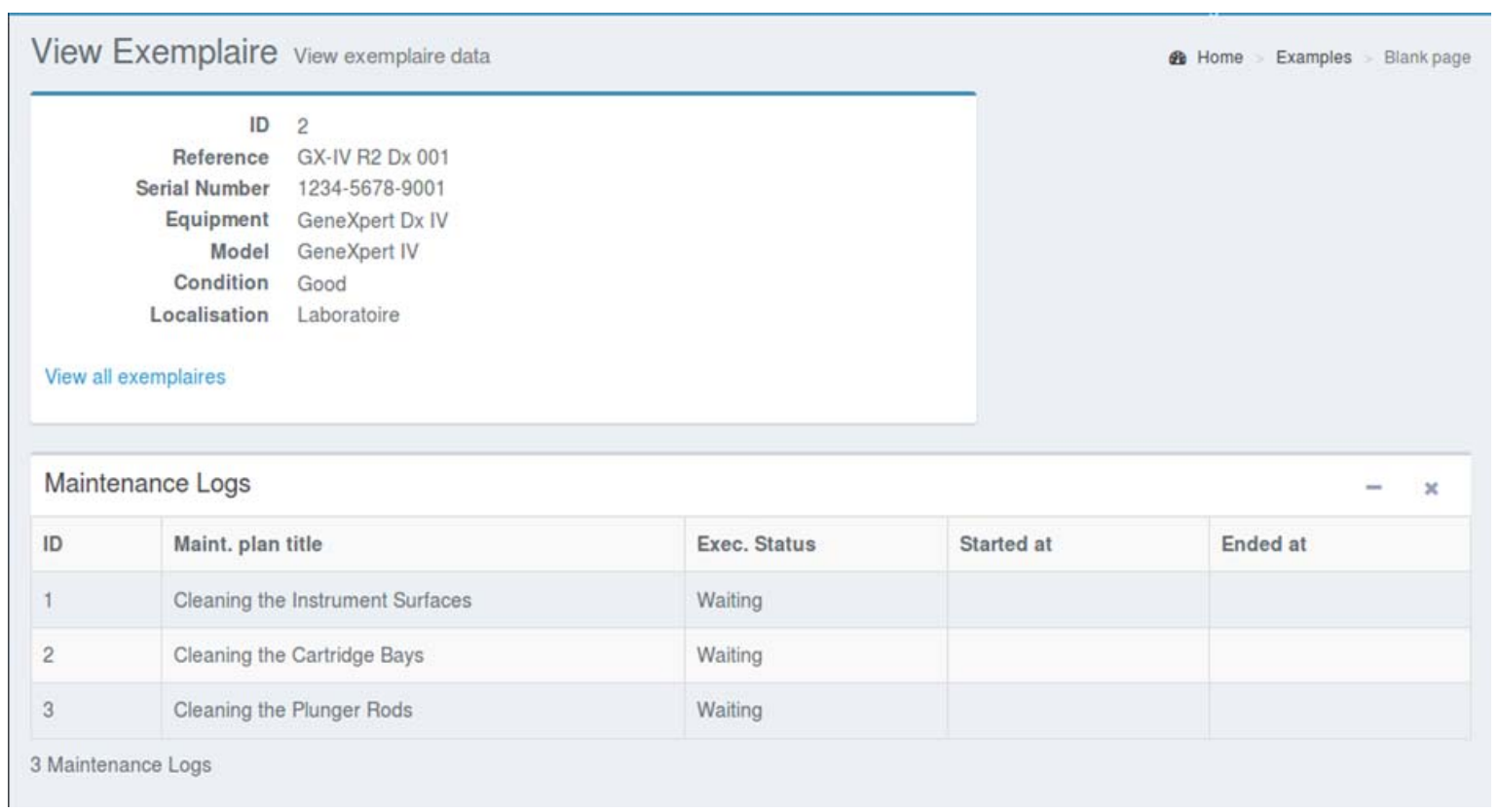

Fig. 5. GeneXpert Dx System GX-IV R2Dx Equipment Maintenance Tracking

Figure 5 shows the logs of GeneXpert DX maintenance activities. Equipment maintenance plans do not change as they are provided by the supplier as a recommendation. As shown in this figure, the actions have a status "Not Performed" when they first appear on this maintenance tracking page. Other pre-existing follow-up actions may have the status "In Progress" or "Completed" depending on their level of execution.

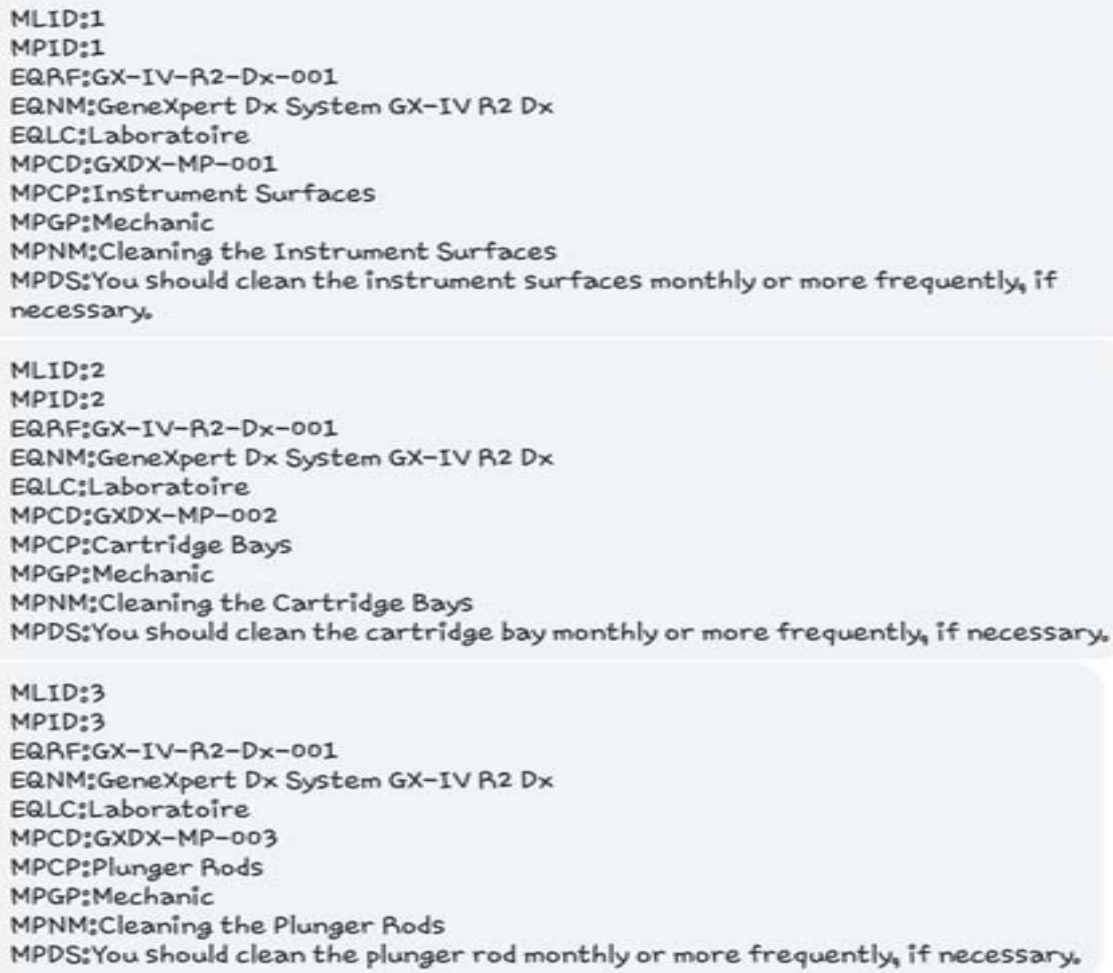

Fig. 6. Maintenance notification messages to be done 
Figure 6 shows three (3) notifications sent by the system, by SMS, to the maintenance operators. These messages are issued as soon as a new maintenance action is required. Each notification includes a sequence of parameters and the corresponding values. The content of the first notification is detailed in Table 2 .

TABLE 2. Details of a notification

\begin{tabular}{|l|l|l|}
\hline Parameters & Values & Meaning \\
\hline MLID & 1 & Maintenance log Id \\
\hline MPID & 1 & Maintenance plan Id \\
\hline EQRF & GX-IV-R2-Dx-001 & Equipment reference \\
\hline EQNM & GeneXpert Dx System GX-IV-R2-Dx & Equipment name \\
\hline EQLC & Laboratory & Equipment location \\
\hline MPCD & GXDX-MP-001 & Maintenance plan reference \\
\hline MPCP & Instrument surfaces & Concerned Equipment component \\
\hline MPGP & Mechanic & Component group of the equipment \\
\hline MPNM & Cleaning the instrument surfaces & Title of maintenance plan \\
\hline MPDS & $\begin{array}{l}\text { You should clean the instrument surfaces monthly } \\
\text { or more frequently, if necessary. }\end{array}$ & Description of maintenance plan \\
\hline
\end{tabular}

Table 2 shows the ten lines of a notification. Each line has three columns: the parameter, its value, and the meaning. For example, line four (4) indicates the name of the device, object of maintenance; while the fifth line shows its location.

\section{*?CMD**MLID:1**MPID:1**MPMR:?**MPPR:?*\#}

Fig. 7. Hardware List Request and Maintenance Procedure

Figure 7 shows the SMS sent by the service technician, to request the materials list (MPMR :?) and details of the maintenance procedure (MPPR :?) for maintenance plan 1 (MPID: 1) and Entry Number 1 of the Maintenance Tracking Table (MLID: 1).

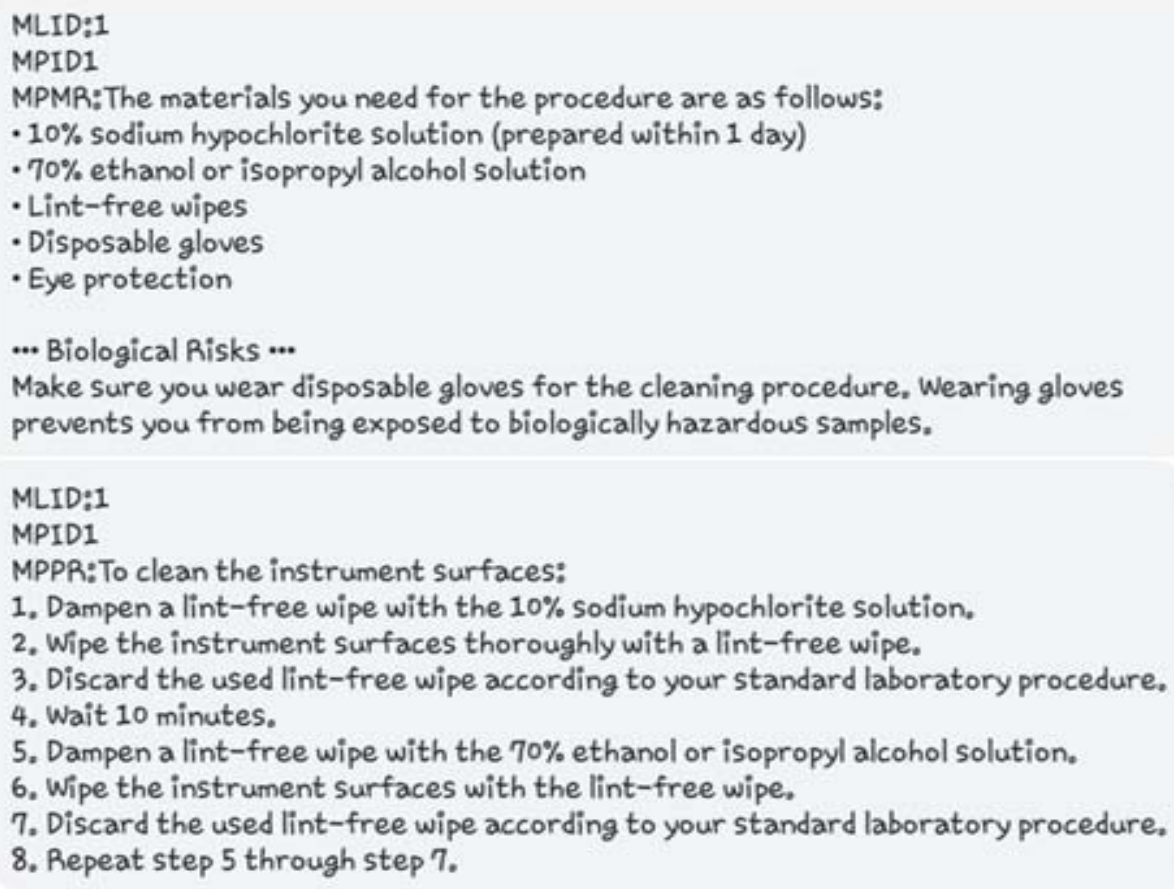

Fig. 8. Query Hardware List and Maintenance Procedure

Figure 8 shows the messages sent by the system, in response to the request received. Indeed, the two (2) SMS received by the technician contain, respectively, the list of the material and the procedure to follow for a good execution of the work. 


\section{*?CMD**MLID:1**MLRQ $=$ RAS*\# \\ n.t. . rue}

Fig. 9. Record of the execution of works

Figure 9 shows the SMS sent by the technician, once the maintenance actions completed, to announce the effectiveness of the execution of the maintenance. The message contains a report stating that the maintenance was performed normally (MLRQ = RAS). The maintenance task (MLID: 1) is thus completed and closed, as shown by the next figures.

\begin{tabular}{|c|c|c|c|c|c|c|c|c|}
\hline \multicolumn{7}{|c|}{ Maintenance Logs List List all Maintenance Logs } & \multicolumn{2}{|c|}{ هome > Examples > Blank page } \\
\hline & ID & Eq. ID & Equip. Ref. & Equip. Loc & Maint. plan title & Exec. Status & Started at & Ended at \\
\hline View & 1 & 2 & GX-IV R2 Dx 001 & Laboratoire & Cleaning the Instrument Surfaces & Completed & $\begin{array}{l}2019-01-30 \\
09: 03: 42\end{array}$ & $\begin{array}{l}2019-01-30 \\
10: 35: 52\end{array}$ \\
\hline View & 2 & 2 & GX-IV R2 Dx 001 & Laboratoire & Cleaning the Cartridge Bays & Waiting & & \\
\hline View & 3 & 2 & GX-IV R2 Dx 001 & Laboratoire & Cleaning the Plunger Rods & Waiting & & \\
\hline \multicolumn{9}{|c|}{3 Maintenance Logs } \\
\hline
\end{tabular}

Fig. 10. Maintenance follow-up after running jobs: MLID task: 1 is "Completed"

Figure 10 shows the entries of the maintenance follow-up table. It shows the start and end dates and times of a maintenance activity, as well as its new status (Completed).

\begin{aligned} & \hline View Maintenance Log View Maintenance Log data \\ & \hline ID 1 \\ & Equip. ID 2 \\ & Equip. Ref GX-IV R2 Dx 001 \\ & Equip. Name GeneXpert Dx IV \\ & Equip. Model GeneXpert IV \\ & Title Cleaning the Instrument Surfaces \\ & Emitted at 2019-03-17 23:38:56 \\ & Status Completed \\ & Started at 2019-01-30 09:03:42 \\ & Ended at 2019-01-30 10:35:52 \\ & Remarks None \\ & \\ & View all Maintenance Log \\ & \hline\end{aligned}

Figure 11. Detail of a maintenance log (MLID: 1) after completion of the work

Figure 11 shows the details of a maintenance follow-up. In addition to the dates and times of start and end of the work, and the status, there is also note (RAS), indicating that the execution of the work went perfectly and there is nothing to report. 
These results show that our solution works. Indeed, we made possible the communication by SMS between a CMMS software and maintenance staff of a health structure. From the notifications sent by the software, to signal maintenance work to be carried out, exchanges ensue until the complete execution of a preventive maintenance activity.

Like our previous work in relation on alert sending [23], the results obtained are encouraging. Although all use cases have not yet been implemented, the current results look promising.

The main limitations of the system, in the current state, notwithstanding the advances presented above, are twofold. Firstly, the data transmitted by SMS are mainly textual, however the user manuals of some equipment include diagram or pictures, related to their maintenance. Secondly the amount of data transmitted by an SMS is low: it makes use of several SMSs for sending some texts.

\section{VI.CONCLUSION}

The literature review has shown that remote access to CMMS software by short messages has never been experienced. In this paper, we propose a solution for remote management of maintenance by SMSs, in a hospital context. The experience of implementation of this solution shows that is viable. And the results obtained, at this stage, pushes us to optimism as to the continuation of the overall project.

As a perspective, it might be possible to overcome the main limitations: SMS transmission of other types of digital media (images, video, sound). To optimize SMS communication, data compression will be considered in our future work.

\section{REFERENCES}

[1] World Health Organization, Série technique de l'OMS sur les dispositifs médicaux: Développement de politiques relatives aux dispositifs médicaux, Genève 27 (Suisse): Editions de l’OMS, 2012.

[2] I. Kullolli, Selecting a Computerized Maintenance Management System, Biomedical Instrumentation \& Technology, Vol. 42, pp.276$278,2008$.

[3] World Health Organization, Série technique de l'OMS sur les dispositifs médicaux: Introduction à la gestion du parc des équipements médicaux, Genève 27 (Suisse): Editions de l'OMS, 2012.

[4] World Health Organization, Série technique de l'OMS sur les dispositifs médicaux: Programme de maintenance des équipements médicaux - presentation générale, Genève 27 (Suisse): Editions de l’OMS, 2012.

[5] World Health Organization, Série technique de l'OMS sur les dispositifs médicaux: Système de gestion de maintenance assistée par ordinateur, Genève 27 (Suisse): Editions de l'OMS, 2012.

[6] T. Baban, Mise en place d'un système de gestion de la maintenance assistée par ordinateur (GMAO): cas de l'Hôpital Central de Yaoundé, M.S. thesis, Département Génie Électrique, Ecole Polytechnique, Université de Yaoundé I, Yaoundé, Cameroun, 2015.

[7] Institut National de la Statistique du Cameroun, Chapitre 21: Postes et télécommunications In: Annuaire Statistique du Cameroun 2015, 2015.

[8] A. Amin and M. N. A. Khan, A Survey of GSM Technology to Control Remote Devices, International Journal of u- and e- Service, Science and Technology, Vol. 7, No. 6, pp. 153-162, 2014.

[9] B. Townsend, J. Abawajy and T.H. Kim, SMS-Based Medical Diagnostic Telemetry Data Transmission Protocol for Medical Sensors, Sensors, Vol. 11, No. 4, pp. 4231-4243, 2011.

[10] M. Rajput, S. Pai and U. Mhapankar, Wireless Transmission of Biomedical Parameters Using GSM Technology, International Journal of Emerging Science and Engineering (IJESE), Vol. 1, No. 9, 2013.

[11] B. Fogg and E. Allen, 10 Uses of Texting to Improve Health in Proceedings of the 4th International Conference on Persuasive Technology, Persuasive '09. ACM, New York, USA, 2009. Vol. 38, pp. 1-6, 2009.

[12] C. L. Tseng, J. A. Jiang, R.G. Lee, F.-M. Lu, C.S. Ouyang, Y.S. Chen and C.-H. Chang, Feasibility study on application of GSM-SMS technology to field data acquisition, Computers and Electronics in Agriculture. Vol. 53, No 1, pp. 45-59, 2006.

[13] S. Dustdar and H. Gall, Architectural concerns in distributed and mobile collaborative systems, Journal of Systems Architecture, Vol. 49, No 10-11, pp. 457-473, 2003.

[14] A. Arnaiz, C. Emmanouilidis, B. Iung, E. Jantunen, Mobile Maintenance Management, Journal of International Technology and Information Management, Vol. 15, No. 4, pp.11-22, 2006.

[15] A. Arnaiz, E. Gilabert, E. Jantunen and A. Adgar, Ubiquitous computing for dynamic condition-based maintenance, Journal of Quality in Maintenance Engineering, Vol. 15, No. 2, pp.151-166, 2009.

[16] V. Guillet, S.P. Sushka and B. Jurkovac, Effectively Improving Maintenance for Water Distribution and Treatment Infrastructure at Central Arkansas Water Through Extensive GIS, CMMS and Mobile Use, in Proceedings of the Water Environment Federation, WEFTEC 2009: Session 101 through Session 110, Vol. 12, pp. 6842-6853, 2009.

[17] C. Emmanouilidis, J. P. Liyanage and E. Jantunen, Mobile solutions for engineering asset and maintenance management, Journal of Quality in Maintenance Engineering, Vol. 15, No. 1, pp.92-105, 2009.

[18] S. Grzegorz and J. K. Bankosz, Mobile technology-enhanced asset maintenance in an SME, Journal of Quality in Maintenance Engineering, Vol. 20, No. 2, pp.163-181, 2014.

[19] J. Zhao, and C. Feng, Design and implementation of mobile operation maintenance management system based on Java EE and Android, in 6th IEEE International Conference on Software Engineering and Service Science (ICSESS), 2015, pp.349-352, 2015.

[20] L. Mihanović, P. Ristov and G. Belamarić, Use of new information technologies in the maintenance of ship systems, Scientific Journal of Maritime Research, Vol. 30, pp.38-44, 2016.

[21] P. Munyensanga, S.A. Widyanto, M.N.A. Aziz, Rusnaldy and Paryanto, Information management to improve the effectiveness of preventive maintenance activities with computerized maintenance management system at the intake system of circulating water pump, Procedia CIRP, 6th CIRP Global Web Conference - Envisaging the future manufacturing, design, technologies and systems in innovation era (CIRPe 2018), Vol. 78, pp. 289-294, 2018.

[22] Google Code Archive, Maintenancedb, The Open Source Computerized Maintenance Management System CMMS, 2012 [In ligne], Available at: <https://code.google.com/archive/p/maintenancedb/> [Consulted on: 09/02/2019].

[23] D. Abessolo Assoumou, A. J. Oyobé Okassa and P. Élé, Proposition d'un prototype de pilotage d'une application de GMAO par SMS, Deuxième Conférence Internationale IUT-Entreprises (IUTENT 2017), 19-21 décembre 2017, Bandjoun, Cameroun. 


\section{AUTHOR PROFILE}

Dieudonné Abessolo Assoumou, Lecturer, Ecole Polytechnique, Université des Sciences et Techniques de Masuku, Franceville, Gabon.

Aimé Joseph OyobeOkassa, Senior Lecturer, Ecole Polytechnique, Université des Sciences et Techniques de Masuku, Franceville, Gabon.

Pierre Élé, Associate Professor, Ecole Polytechnique, Université de YaoundéI, Cameroun; IUT, Université de Douala, Cameroun. 